\title{
PLAGIOCEPHALY IN SOME 10-YEAR-OLD CHILDREN
}

\author{
BY \\ P. M. DANBY \\ From the Department of Human Anatomy, University of Oxford
}

(RECEIVED FOR PUBLICATION MAY 21, 1962)

Cranial asymmetry of the type known as plagiocephaly occurs frequently in infants and in adults (Clark, 1934; Orley, 1949; Potter, 1952). Very little precise information is available concerning the cause, or more probably the multiple causes, of this kind of cranial malformation. The term plagiocephaly signifies the flattening of diagonally opposite areas of the frontal and occipital bones, resulting in the slanting of the entire cranial outline in norma verticalis (Fig. 1). The condition is clinically unimportant. No functional disability appears to be associated with it. The double asymmetry involved does, however, raise an interesting problem in the dynamics of cranial growth.

Some observations concerning cranial development in plagiocephalic children have been made in connexion with the Child Health Survey begun in Oxford in 1945. The condition was noted in approximately $5 \%$ of the infants between birth and 1 year of age taking part in this survey. It has been possible to re-examine some of these boys and girls approximately 10 years later, in 1956/57. The average age of the sample examined in 1956/57 was 9.8 years, with a range from 8 years to 11.5 years.

Answers were sought to the following questions:

1. Do growth processes during the first decade of life eliminate all traces of infantile plagiocephaly?

2. Are there any factors in the antenatal records of these children which could be considered to cause or contribute to this condition?

\section{Method}

A full axial projection radiograph with the head extended and with the central beam approximately perpendicular to the standard horizontal plane of the head was obtained for each child.

Antenatal records provided the main source of information in the case histories, augmented by birth records.

The small size of the sample, 21 in number, made statistical treatment problematical. Fisher's Exact
Test for $2 \times 2$ Tables (Fisher, 1956) was used, being considered the most satisfactory test available for a sample of this size.

\section{Results}

Inspection of the radiographs for degree and type of asymmetry yielded the information set out in Table 1.

TABLE 1

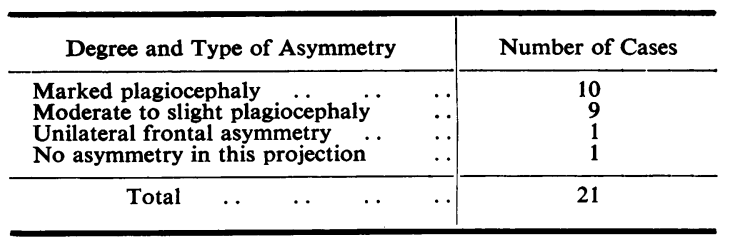

Of 21 cases, 19 or $90 \%$ of the sample were still plagiocephalic at 10 years of age.

It is clear from Fig. 1 that the cranial outline of a plagiocephalic cranium in norma verticalis may be slanted either to the right or to the left, and both types of plagiocephaly are included in the present sample (Table 3). This double asymmetry implies a causative factor which must itself be right- and left-handed, although it might be either external or internal in relation to the infant cranium. The most obvious of possible external causes that fulfils these conditions is perhaps the maternal pelvis. Fig. 2 shows in diagrammatic form the spatial relation between the maternal pelvis and the foetal head in the four most usual types of vertex presentation. When the head enters the pelvic brim, a few weeks to a few days before birth in most cases, mechanical pressures resulting from the weight of the foetus are likely to fall on the frontal and occipital bones where they come into contact with the pubis and the ileopectineal region of the ileum, as shown in Table 2.

Because of the varying degree of detail available in the antenatal records, two sets of data relating to the position of the foetus have been compiled. All cases considered were vertex presentations. 

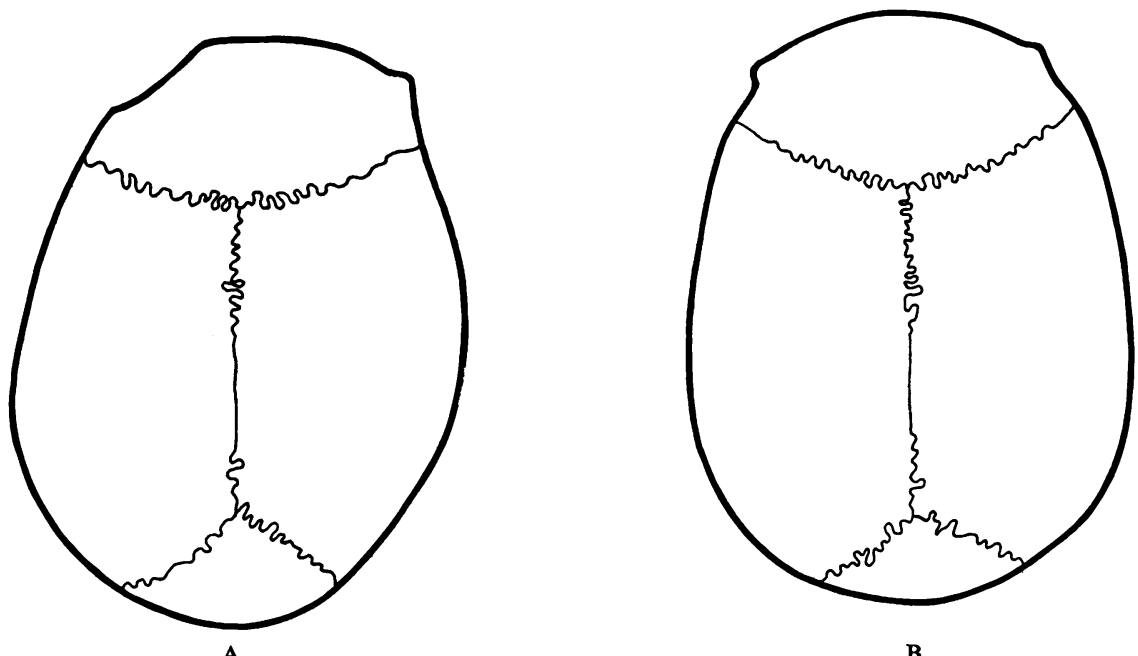

B

FIG. 1.-Outline in norma verticalis. A. Plagiocephalic cranium; B. Normal cranium.

Version had been performed on two cases at $2 \frac{1}{2}$ and 6 weeks before delivery, respectively. These two cases are not included in Table 3(A), which summarizes data for the 10 cases considered to be the best documented and most reliable. The cases in
Table 3(A) are included in Table 3(B) with the less well-documented individuals. The one case shown in Table 1 having unilateral frontal asymmetry only has been excluded from Table 3 altogether, as also was a case without sufficient documentation. The
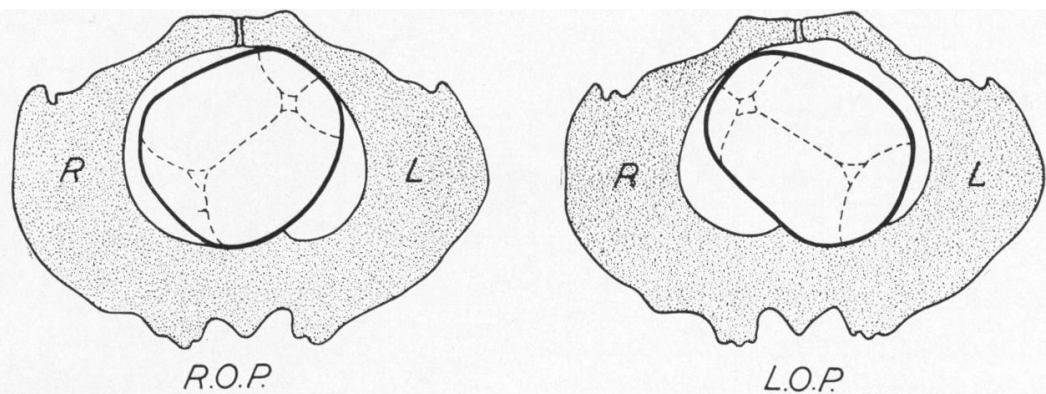

L.O.P.
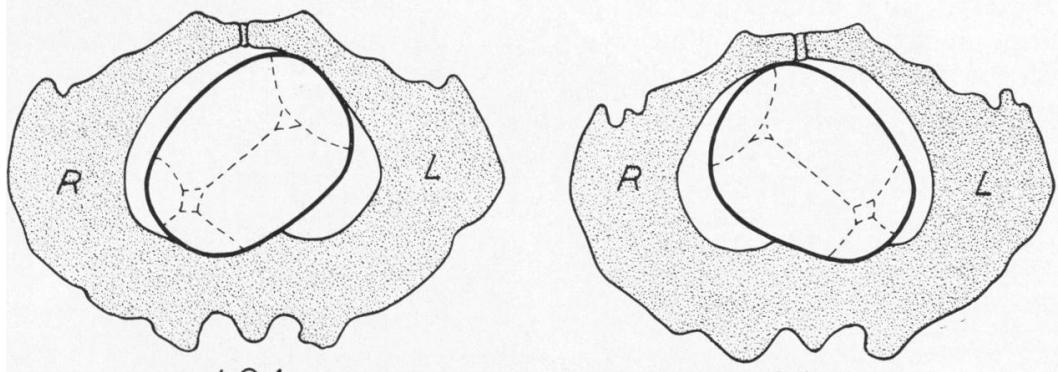

L.O.A.

R.O.A.

FIG. 2.-Diagrammatic representation of the position of the foetal head in the maternal pelvic brim, in the four most usual vertex presentations (seen from below). (From Williams' Obstetrics, 11th ed.)

ROP -right occipito-posterior.

LOA-left occipito-anterior.

LOP - left occipito-posterior.

ROA-right occipito-anterior. 
TABLE 2

\begin{tabular}{l|c}
\hline \multicolumn{1}{c|}{ Foetal Position } & Cranial Bones of Foetus Involved \\
\hline $\begin{array}{l}\text { Left occipito-anterior } \\
\text { Right occipito-posterior }\end{array}$ & $\begin{array}{l}\text { Left frontal and right occipital } \\
\text { Left frontal and right occipital }\end{array}$ \\
$\begin{array}{l}\text { Right occipito-anterior } \\
\text { Left occipito-posterior }\end{array}$ & $\begin{array}{l}\text { Right frontal and left occipital } \\
\text { Right frontal and left occipital }\end{array}$ \\
\hline
\end{tabular}

usual distribution of vertex presentations between left- and right-handed positions is quoted by Johnstone and Kellar (1955) as $85 \%$ left occipitoanterior (LOA) to right-occipito posterior (ROP) and $15 \%$ ROA-LOP: this distribution accords roughly with the data in Table 3. Unfortunately the ROA-

TABLE 3

\begin{tabular}{c|c|c|c}
\hline $\begin{array}{c}\text { Position of } \\
\text { Foetal Head } \\
\text { Before and At Birth }\end{array}$ & \multicolumn{2}{|c|}{$\begin{array}{c}\text { Flattening of Cranial Outline in } \\
\text { Norma Verticalis Observed at 10 Years }\end{array}$} \\
\cline { 2 - 4 } & $\begin{array}{c}\text { Right Frontal } \\
\text { Left Occipital }\end{array}$ & $\begin{array}{c}\text { Left Frontal } \\
\text { Right Occipital }\end{array}$ & Total \\
\hline $\begin{array}{c}\text { (A) } \begin{array}{c}\text { LOA or ROP } \\
\text { ROA or LOP }\end{array} \\
\text { Total }\end{array}$ & 2 & 7 & 9 \\
\hline (B) LOA or ROP & 1 & 0 & 1 \\
\hline ROA or LOP & 3 & 7 & 10 \\
\hline Total & 2 & 11 & 13 \\
\hline
\end{tabular}

LOP group is inevitably very sparsely represented in such a small sample. Statistical treatment of such limited data is of doubtful value. Fisher's Exact Test for $2 \times 2$ tables yields a $10 \%$ significance level in favour of an association between the general position of the foetus during the last few weeks of pregnancy and at birth, and the type of plagiocephaly shown.

The length of time between the descent of the foetal head into the pelvic brim and parturition, and also the degree to which the head remains fixed during the last weeks of pregnancy are very relevant to the present inquiry. It is understood that prenatal examinations at the antenatal clinics were usually done with the mother in the prone position. In these circumstances the infant head tends to move upwards in the abdominal cavity, and it is therefore probable that the time factor has been underrather than overestimated. Table 4 shows the

TABLE 4

DEGREE OF PLAGIOCEPHALY IN RELATION TO AVERAGE LENGTH OF STAY IN FIXED POSITION IN PELVIC BRIM

\begin{tabular}{|c|c|c|}
\hline $\begin{array}{l}\text { Degree of } \\
\text { Plagiocephaly }\end{array}$ & $\begin{array}{l}\text { No. of } \\
\text { Cases }\end{array}$ & $\begin{array}{l}\text { Average Duration in } \\
\text { Pelvic Brim (days) }\end{array}$ \\
\hline $\begin{array}{l}\text { Marked .. } \\
\text { Moderate to slight } \\
\text { None }\end{array}$ & $\begin{array}{l}8 \\
7 \\
1\end{array}$ & $\begin{array}{l}19 \cdot 6 \\
9 \cdot 7 \\
0\end{array}$ \\
\hline
\end{tabular}

average number of days in the pelvic brim in relation to the degree of plagiocephalic malformation.

Three cases had to be omitted from Table 4 for want of data. One case was omitted because the period for which the head was recorded as fixed was exceptionally long (62 days) and would unduly have influenced the mean in so small a sample. This case was marginal in severity between the first two groups in Table 1. These figures suggest that a consistently maintained attitude of the foetal head may be related to the severity of the plagiocephaly observed at 10 years.

The mothers of 12 out of the 21 children in the sample were primigravidae. Among 16 cases for whom appropriate records were available at least seven were more than two weeks overdue, and all but one, a 36-week pregnancy, were at term or later. The average weight of 17 babies was $7 \mathrm{lb} .7 \mathrm{oz}$. $(3.27 \mathrm{~kg}$.). There were two cases, not included in the statistical sample, which were breech deliveries showing some plagiocephaly. These cases are discussed at a later stage.

\section{Discussion}

Little appears to be known of the causes of infant or of adult plagiocephaly. The explanation sometimes offered for the adult condition is deranged synostosis of the cranial sutures (Orley, 1949; Potter, 1952). The object of this study was to find out if the condition persisted from infancy to adolescence, and if any predisposing antenatal factors could be isolated.

The data in Table 1 show that the condition does persist in $90 \%$ of the sample, and the first question posed in the introduction to this paper is therefore answered in the negative. In the more severe cases the asymmetry of the vault was clearly discernible on superficial examination by eye and by palpation. Plagiocephaly may be said, therefore, to survive the massive changes in size and shape of the cranium during the first two years of life and to continue into early adolescence. The cranium experiences a second growth spurt during adolescence and we do not yet know what effect this might have on a plagiocephalic cranium, but it may reasonably be supposed that the condition will survive into adulthood.

The question remains as to the primary causes of plagiocephaly. The condition was first noted in the cases under review at times ranging between the first and the twelfth month after birth. It is not known whether the condition was observable at birth. Malformations of the infant head at birth are various (Moir, 1956; Eastman, 1956) and are most often attributed to the stresses of labour and 
delivery. These vary mainly with the type of presentation, duration of labour, and degree of ossification of the foetal head. There are many other factors which may also be of importance in occasioning malformation of the head at birth. These include pressures resulting from the smallness, or asymmetries, of the maternal pelvis (Moir, 1956); malformations of the uterus; pressures from the sacral promontory; exceptional pressures resulting from the premature loss of amniotic fluids; fractures and depressions caused by surgical intervention and the use of forceps, or by extreme uterine contractions. It is usually held that moulding effects occasioned at birth are transitory and disappear within a few weeks (Moir, 1956; Eastman, 1956). It may be worth noting here that the single plagiocephalic case in the present sample which reverted to a normal cranial outline had suffered severe stresses at birth. Duration of labour was 38 hours and the infant experienced asphyxia livida.

Apart from the phenomena associated with birth itself, certain typical, but statistically undetermined, configurations of the head, associated with different prenatal positions of the foetus, have been described, e.g. the flattening of the vertical region of the head observed in breech cases that have lain with the vault against the fundus of the uterus for a considerable time (Moir, 1956). In this connexion the two plagiocephalic breech delivery cases mentioned above must be considered. This type of effect might be regarded as the natural prenatal equivalent of the head-binding at birth traditionally practised by various peoples (Blackwood and Danby, 1955) and which certainly frequently occasion permanent changes in cranial shape.

Premature and irregular closure of parts of the sagittal suture is the only causative factor of plagiocephaly mentioned by Orley (1949) and Potter (1952); neither of these authors quotes cases or statistics. This explanation would not suffice for any of the cases quoted in this paper. It nevertheless seems very probable that plagiocephaly may be occasioned by more than one type of mechanical stress or physiological disorder. In attempting to outline possible causes it is necessary to recall that plagiocephaly is a double asymmetrical condition, and that the causative stresses must be able to act on the cranium in this specialized way. On this basis a variety of additional contributory factors can be considered.

The possibility of an hereditary predisposition to plagiocephaly cannot be ruled out. No information is available concerning the cranial forms of other members of the families concerned in this study. Each individual came from a different family. In this connexion one curious and probably entirely unrelated fact was observed. Of the 12 mothers whose blood groups were known, eight belonged to blood group $\mathrm{O}$, and seven of these were $\mathrm{Rh}_{1}$. It must be remembered that any attempts to correlate single-gene factors with polygenic physical characters is extremely hazardous. An hereditarily determined high level of foetal ossification might, however, tend to establish a particular cranial pattern acquired during intrauterine growth.

Physiological disturbances of growth control due to dietary or other external causes might be most likely to result in bilateral or simple unilateral malformations. Macalister (1898) held the opinion that brain growth was a major factor in the expansion of the parietal region of the cranium towards the end of the first year of life. Bulging of the parietal region of the same side as the depressed occipital bone was observed in many of the cases considered in this paper. Uneven development of the parietal lobes of the cerebral cortex might possibly play some part in perpetuating plagiocephaly. Alternatively, and more probably, the expansion of the parietal might be a secondary effect produced by the depression of the occipital.

Included among the cases considered, but not included in Table 3(A), were three forceps extractions, one version under anaesthetic, and one case of disproportion followed by caesarian lower section. These five cases all showed marked plagiocephaly at approximately 10 years of age. Another case which suffered manual version about six weeks before delivery showed only slight plagiocephaly. Whether or not this malformation is in any way connected with surgical intervention it is not possible to say, but this factor must at least be considered as a possible contributory cause.

The data in Table 3(A) suggest quite clearly that pressures from the maternal pelvis are likely to comprise one of the causative factors of plagiocephaly. The evidence that the type of plagiocephaly and the position of the foetus are related, is tangible, but a much larger sample would be needed to achieve an unequivocal answer on this point. A relation between the severity of the malformation and the period during which the foetal head was fixed in the pelvic brim is rather more clearly demonstrated in Table 4. This provides valuable corroborative evidence to the whole hypothesis of a relation between the maternal pelvis and plagiocephaly at 10 years.

\section{Summary}

A small sample of 10-year-old children of both sexes in whom plagiocephaly had been observed in 
early infancy were examined by means of radiographs of the head in the standard horizontal plane. The presence of plagiocephaly in 19 out of 21 cases, i.e. $90 \%$ of the sample, was established. That this condition persists from infancy into adolescence is therefore put on iecord.

Various causative factors are discussed. The likelihood of a relation between the position of the foetus in the pelvic brim and the orientation of the plagiocephaly observed at 10 years is established at a $10 \%$ significance level.

I am very grateful to Professor Sir Wilfred Le Gros
Clark, F.R.S. for his interest and help and to Dr. F. H. Kemp for the radiographs.

\section{REFERENCES}

Blackwood, B. and Danby, P. M. (1955). A study of artificial cranial deformation in New Britain. $J$. roy. anthrop. Inst. 85, 173.

Clark, W. E. Le Gros (1934). The asymmetry of the occipital region of the brain and skull. Man, 34, 35 .

Eastman, N. J. (1956). Williams Obstetrics, 11th ed. Appleton Century-Crofts, New York.

Fisher, R. A. (1956). Statistical Methods and Scientific Inference. Oliver and Boyd, Edinburgh.

Johnstone, R. W. and Kellar, R. J. (1955). A Text-book of Midwifery, 16th ed. Black, London.

Macalister, A. (1898). The causation of brachy- and dolichocephaly. J. Anat. Physiol. (Lond.), 32, 334.

Moir, J. Chassar (1956). Munro Kerr's Operative Obstetrics, 6th ed. Baillière, Tindall and Cox London.

Orley, A. (1949). Neuroradiology. Blackwell, Oxford.

Potter, E. L. (1952). Pathology of the Fetus and the Newborn. Year Book Publishers, Chicago. 